\title{
Enumeration of Mycobacterium avium subsp. paratuberculosis by quantitative real-time PCR, culture on solid media and optical densitometry
}

\author{
Petr Kralik*, Vladimir Beran and Ivo Pavlik
}

\begin{abstract}
Background: Different approaches are used for determining the number of Mycobacterium avium subsp. paratuberculosis (MAP) cells in a suspension. The majority of them are based upon culture (determination of CFU) or visual/instrumental direct counting of MAP cells. In this study, we have compared the culture method with a previously published F57 based quantitative real-time PCR (F57qPCR) method, to determine their relative abilities to count the number of three different MAP isolates in suspensions with the same optical densities (OD). McFarland turbidity standards were also compared with F57qPCR and culture, due to its frequent inclusion and use in MAP studies.

Findings: The numbers of MAP in two-fold serial dilutions of isolates with respective OD measurements were determined by F57qPCR and culture. It was found that culture provided lower MAP CFU counts by approximately two $\log _{10}$, compared to F57qPCR. The McFarland standards (as defined for E. coli) showed an almost perfect fit with the enumeration of MAP performed by F57qPCR.

Conclusions: It is recommended to use culture and/or qPCR estimations of MAP numbers in experiments where all subsequent counts are performed using the same method. It is certainly not recommended the use of culture as the standard for qPCR experiments and vice versa.
\end{abstract}

\section{Findings}

The sensitivity of detection of Mycobacterium avium subsp. paratuberculosis (MAP) in different matrices is linked to the number of bacteria present. However, determining the exact number of MAP cells in a sample is complicated with no real consensus on an approved method within the scientific community. Several methods have been suggested for the enumeration of MAP in routine diagnostics and laboratory experiments. Culture on solid media with subsequent counting of colony forming units (CFU) is the most widely used method [1]. Unfortunately, a major problem encountered with this method is the long incubation period required to grow MAP as well as its tendency to form clumps when culturing in broth in vitro. Despite this, culture is presently the only method that can provide quantitative data on the number of viable MAP cells in a sample. It is used as the quantification

\footnotetext{
* Correspondence: kralik@vri.cz

Veterinary Research Institute, Hudcova 70, 62100 Brno, Czech Republic
}

standard for the optimization of PCR methods and DNA isolation procedures from milk and faeces $[2,3]$.

Another possible method how to assess the number of MAP cells in a sample is visual or instrumental counting of individual cells. Visual counting of MAP cells under a microscope can serve as a confirmatory method to culture $[3,4]$. Instrumental counting of MAP cells can be performed using a haemocytometer or flowcytometer $[5,6]$. MAP can also be successfully enumerated by the quantitative real-time PCR (qPCR) method based upon the single copy fragment F57 [7,8]. Compared to culture, these counting methods assess the number of MAP cells independently from their viability.

In order to assess the approximate number of bacteria in a sample quickly and easily, turbidity measurements were introduced. Optical densities (OD) of the bacterial suspensions were determined at wavelengths between the range 550 to $600 \mathrm{~nm}$, which corresponds to the bacterial absorption maximum of the sample [9]. For MAP there have been several equations used to calculate the
C Bïomed Central

(C) 2012 Kralik et al; licensee BioMed Central Ltd. This is an Open Access article distributed under the terms of the Creative Commons Attribution License (http://creativecommons.org/licenses/by/2.0), which permits unrestricted use, distribution, and reproduction in any medium, provided the original work is properly cited. 
number of MAP cells from OD readings. Janagama et al. (2006) stated that $\mathrm{OD}_{600 \mathrm{~nm}}=0.3$ is equal to $10^{9}$ MAP $\mathrm{CFU} / \mathrm{ml}$ of suspension [10]. Bogli-Stuber et al. (2005) counted MAP according to the equation $\mathrm{OD}_{540 \mathrm{~nm}}=$ 0.65 corresponds to $4 \times 10^{8} \mathrm{CFU} / \mathrm{ml}$ [11]. In contrast, Chui et al. (2004) used the formula $\mathrm{OD}_{550 \mathrm{~nm}}=1$ is equivalent to $2.8 \times 10^{6}-10^{7} \mathrm{MAP}$ cells $/ \mathrm{ml}$ of suspension [12].

An alternative variant of turbidity measurements are the McFarland standards [13]. The bacterial suspensions are then visually compared to the McFarland standards estimating the bacterial density. For E. coli, a $0.5 \mathrm{McFar}-$ land standard corresponds to $1.5 \times 10^{8} \mathrm{CFU} / \mathrm{ml}$ [9]. This technique is widely used in microbiology and has been adopted for MAP $[5,14]$.

The heterogeneity of MAP enumeration using OD measurements, combined with the lack of direct comparison with culture and individual cell counting methods brings forward the additional problem of interpreting results from different laboratories. The aim of this study was to compare two distinct methods of MAP quantification, culturing on solid media and F57qPCR, for their ability to quantify the number of MAP cells in serially diluted aliquots of three different MAP isolates with identical $\mathrm{OD}_{600 \mathrm{~nm}}$ readings. In accordance with routine laboratory practice, McFarland turbidity standards were prepared, their exact OD were determined and the theoretical amount of bacterial cells [9] was compared with F57qPCR and culture results to assess its applicability for the enumeration of MAP.

\section{Materials and methods Preparation of MAP isolates}

All three MAP isolates used in this study were obtained from cow faeces and tissues at the Veterinary Research Institute (Brno, Czech Republic) and belonged to the RFLP type C1. Isolates 8819 and 8672 were both passaged five times and produced visible colonies within 8 weeks on Herrold's Egg Yolk Medium (HEYM) with Mycobactin J (Allied Monitor, Fayette, MO, USA) with the antibiotics penicillin G, chloramphenicol and amphotericin B. Isolate 12146 was passaged more than 10 times and produced colonies on HEYM with supplements in under 6 weeks. A single colony from each isolate was inoculated into liquid Middlebrook 7H9 broth (DIFCO, Livonia, MI, USA), supplemented with Middlebrook OADC enrichment (DIFCO) and Mycobactin J (Allied Monitor) and then cultured for up to 5 weeks at $37^{\circ} \mathrm{C}$, to avoid excessive cell clumping.

Aliquots of $50 \mathrm{ml}$ from each MAP isolate in liquid medium were centrifuged at $7000 \mathrm{~g}$ for $2 \mathrm{~min}$, subsequently discarding the supernatant. The pellets were resuspended in the remaining supernatant (approximately $1 \mathrm{ml}$ ) and transferred to $2 \mathrm{ml}$ screw cap tubes, each containing twelve $1 \mathrm{~mm}$ zirconia silica beads (Biospec, Bartlesville, OK, USA), vortexed at full speed for $10 \mathrm{~s}$ and centrifuged at $100 \mathrm{~g}$ for $30 \mathrm{~s}$. These steps were carried out to minimize the number of MAP clumps in cell suspensions. The presence of MAP clumps in each MAP suspension was checked using Ziehl-Neelsen staining and optical microscopy.

\section{Optical density determination}

Each suspension of MAP isolate was two-fold serially diluted in Middlebrook 7H9 medium in seven succeeding steps to ensure that zero OD was reached. Each dilution was split into three aliquots of $500 \mu \mathrm{l}$ and in portion of each of them $(60 \mu \mathrm{l})$ absorbance at $600 \mathrm{~nm}$ was recorded (Biophotometer, Eppendorf, Hamburg, Germany). The remainder of the aliquots was used for F57qPCR and culture. Middlebrook 7H9 medium was used as the blank.

\section{Determination of the absolute number of MAP in diluted suspensions by F57qPCR}

Three aliquots of $200 \mu \mathrm{l}$ from the two-fold diluted MAP suspensions were centrifuged at $7000 \mathrm{~g}$ for $2 \mathrm{~min}$, the supernatant was removed by pipetting and the pellet was resuspended in $300 \mu \mathrm{l}$ of Tris-EDTA (TE) buffer supplemented with Fish Sperm DNA (Serva, Heidelberg, Germany) at a concentration of $50 \mathrm{ng} / \mu \mathrm{l}$. After the addition of $350 \mathrm{mg}$ of $0.1 \mathrm{~mm}$ zirconia silica beads (Biospec) the MAP cells were lysed using a MagNA Lyser (Roche Molecular Diagnostic, Manheim, Germany) at $6400 \mathrm{rpm}$ for $60 \mathrm{~s}$. The lysed MAP cells were centrifuged at $18000 \mathrm{~g}$ for $5 \mathrm{~min}$ and the supernatant was then used as the template for qPCR, amplifying the single copy fragment $F 57$ [7]. The absolute quantity of MAP cells was determined according to the calibration curve, derived from 10-fold dilutions of plasmid standards containing the F57qPCR product insert in the range from $5 \times 10^{5}$ to $5 \times 10^{0}$ copies per F57qPCR reaction [7].

\section{Determination of MAP CFU counts in diluted suspensions by solid culture}

Three aliquots from each serial two-fold dilution were immediately after OD determination diluted 1:100 in Middlebrook 7H9 in two consecutive steps for the purpose of CFU number determination by culture. One hundred micro litres of the undiluted and diluted solutions (1:100 and 1:10 000) were precisely spread on HEYM with Mycobactin J and antibiotics and incubated at $37^{\circ} \mathrm{C}$ for 3 months.

\section{Comparison of F57qPCR and culture with statistical evaluation of the results}

Mean OD values of each isolate suspension were calculated from the triplicate aliquots prepared for the 
determination of absorbance. These values were plotted against the $\log _{10}$ of the mean absolute numbers of MAP and CFU gained by F57qPCR and culture (semi-logarithmic plot), respectively. The linearity of F57qPCR and culture methods was checked by calculating the square Spearman's rank correlation coefficient $\left(R^{2}\right)$. To compare the MAP numbers gained by F57qPCR and culture with McFarland turbidity standards, standards of $0.5,1$ and 2 McFarland were included in the plot. The optical density of each McFarland standard was measured and paired with an estimated bacterial cell density (number of CFU of E. coli) according to the following approximations: McFarland $0.5=1.5 \times 10^{8} \mathrm{CFU} / \mathrm{ml}$, McFarland 1 $=3.0 \times 10^{8} \mathrm{CFU} / \mathrm{ml}$ and McFarland $2=6.0 \times 10^{8} \mathrm{CFU} /$ $\mathrm{ml}[9]$.

Because it was not possible to asses normality of data from triplicates Mann-Whitney Test was used to evaluate statistically results gained by F57qPCR and culture for the relevant dilution and isolate. $P$-values lower than 0.05 were considered statistically significant. The differences in logarithms of absolute counts between F57qPCR and culture data were expressed as logarithm of quotient of mean absolute counts from F57qPCR and mean CFU counts from culture.

\section{Results and discussion}

Despite all attempts to reduce the number of MAP clumps, in all three MAP isolates there were still several units or even tens of small clumps present, visible after staining with Ziehl-Neelsen and optical microscopy. From this, we can conclude that it is very difficult to get rid of all MAP clumps in a suspension making data from culture and qPCR incomparable.

The absolute numbers of MAP determined by F57qPCR were approximately two $\log _{10}$ greater than the $\mathrm{CFU}$ counts from culture at respective ODs (Figure 1) and a highly significant statistical difference $(P<0.0001)$ between all the compared samples was observed. This trend was characteristic for all three MAP isolates used in the study allowing us to exclude any possible differences in the in vitro viability of the cells at the isolate level. Moreover, it is in concordance with previous observations when quantification methods that do not distinguish between viable and dead cells (visual and instrumental counting and qPCR) provide higher absolute numbers of MAP compared to CFU counts using the culture method [5,7].

The mean differences between F57qPCR and culture data was 1.58 for isolate $8819,2.00$ for isolate 8672 and 2.13 for isolate 12146 in $\log _{10}$. The difference between F57qPCR and culture method can be explained by the formation of MAP clumps and the viability of MAP. It was previously hinted that MAP counting using the culture method could be affected by cell clumping, which can lead to an underestimation of MAP cells due to CFU's arising from more than 1 cell. This hypothesis is

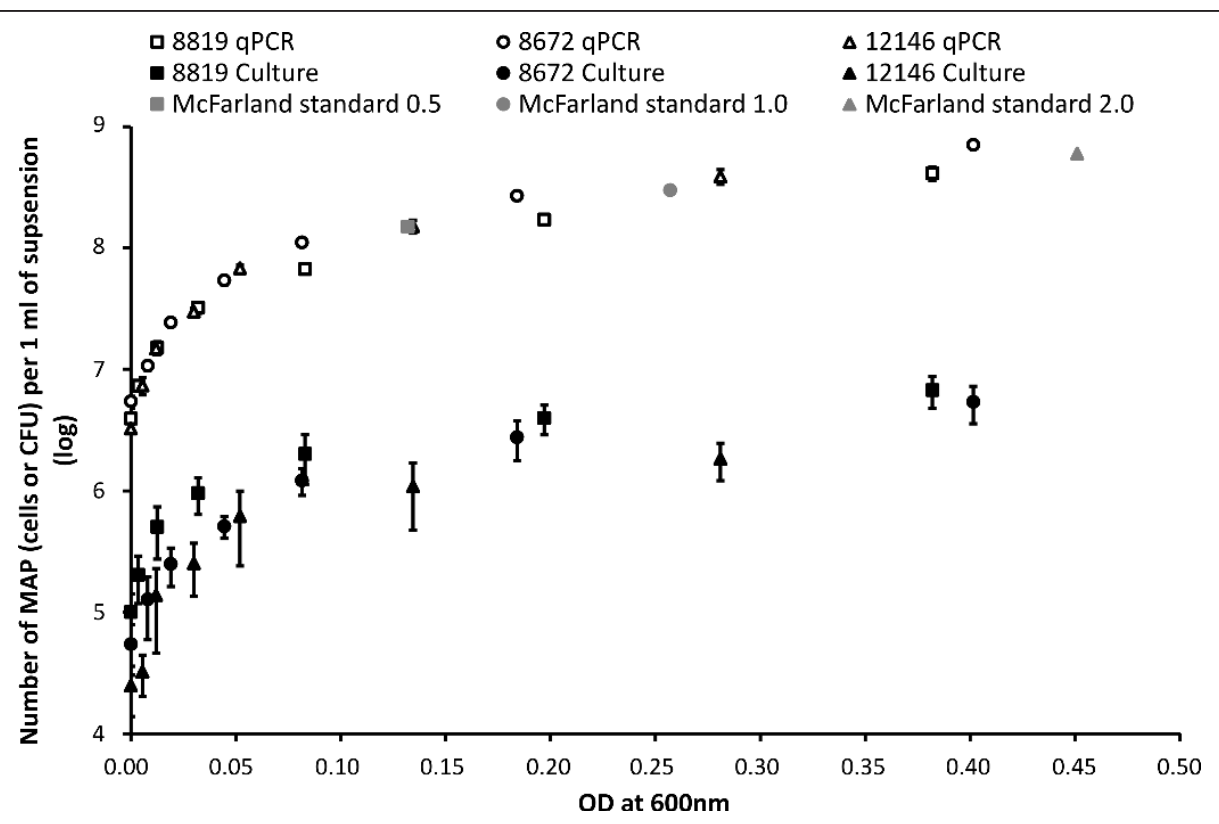

Figure 1 Semilogarithmic graph comparing enumeration of three Mycobacterium avium subsp. paratuberculosis (MAP) isolates. White symbols represent absolute MAP numbers of three MAP isolates gained by F57 based qPCR for the respective OD and dark symbols represent CFU numbers gained by culture. Error bars represent standard deviations obtained from three independent physical replicates. McFarland standards $0.5,1$ and 2 are shown by grey symbols. The OD of each McFarland standard was determined in this study; theoretical number of bacterial cells was adopted according to the standard formula for E. coli: McFarland $0.5=1.5 \times 10^{8} \mathrm{CFU} / \mathrm{ml}[9]$. 
supported by the fact that colonies on the same plate grow at different rates and are different sizes [15].

The other major factor influencing the discrepancy in results between the two methods is visualisation of both viable and non-viable cells. Due to the fact that culture can visualise viable $M A P$ cells only, the reduction of culture counts can be assumed. A MAP suspension, which should correspond to McFarland $10^{9} \mathrm{CFU} / \mathrm{ml}$, was determined to contain only $2.3 \times 10^{8} \mathrm{CFU} / \mathrm{ml}$ [16].

The dependence of OD and F57qPCR or CFU numbers was shown to be linear and all square Spearman's rank correlation coefficients were close to 1 (Table 1 ). The limit of detection for OD MAP enumeration by F57qPCR was similar for all isolates and reached approximately $4 \times 10^{6}$ MAP cells per ml, whereas for culture it was lower at $3 \times 10^{4} \mathrm{CFU} / \mathrm{ml}$ (Table 1).

MAP quantification using the culture method therefore cannot be used as the reference method for qPCR and vice versa. It is necessary to choose a suitable quantification method with respect to the application of experimental data. This must be taken into account particularly when spiking food or faecal matrices with MAP to determine the limit of detection (LOD) of PCR and qPCR methods. According to the results of this study, using such "inaccurate" MAP number determination methods can lead to gross underestimations of the LOD for the respective PCR or qPCR system $[2,3,11,17]$.

This study provides a model for estimating the number of MAP cells in liquid media, through measuring its OD. According to Table 1 and Figure 1, one can use OD measurements to assess quickly an approximate number (CFU) of MAP in a sample. This model is flexible because it does not require the dilution of the sample to an exact $\mathrm{OD}$, as is required using the fixed equations [10-12] or McFarland standards. Perfect fits of F57qPCR MAP numbers and theoretical CFUs of E. coli at respective ODs strengthen the reliability of F57qPCR enumeration and highlight the problems with quantification of MAP by culture (Figure 1). However, if the model were to be functional, samples would have to be prepared identically to the procedure described in the Materials and Methods. Failure to do so is likely to lead to a gross underestimation of MAP numbers or CFUs, due to MAP cells tendency to form clumps.

Table 1 Comparison of recovery of Mycobacterium avium subsp. paratuberculosis by real-time PCR and culture

\begin{tabular}{|c|c|c|c|c|c|c|c|c|}
\hline \multirow[t]{2}{*}{ Isolate } & \multirow[t]{2}{*}{$\mathrm{OD}^{a}$} & \multicolumn{3}{|l|}{ F57qPCR } & \multicolumn{3}{|l|}{ Culture } & \multirow[t]{2}{*}{ Difference $^{f}$} \\
\hline & & Copies $/ \mathrm{ml}^{b}$ & $\mathrm{SD}^{c}$ & $\mathrm{SC}^{d}$ & $\mathrm{CFU} / \mathrm{ml}^{e}$ & $\mathrm{SD}^{c}$ & $\mathrm{SC}^{d}$ & \\
\hline \multirow[t]{7}{*}{8819} & 0.382 & $4.13 \times 10^{8}$ & $5.24 \times 10^{7}$ & 0.972 & $6.77 \times 10^{6}$ & $2.01 \times 10^{6}$ & 0.994 & 1.79 \\
\hline & 0.197 & $1.71 \times 10^{8}$ & $5.43 \times 10^{6}$ & & $3.98 \times 10^{6}$ & $1.10 \times 10^{6}$ & & 1.63 \\
\hline & 0.083 & $6.69 \times 10^{7}$ & $5.73 \times 10^{6}$ & & $2.02 \times 10^{6}$ & $8.84 \times 10^{5}$ & & 1.52 \\
\hline & 0.032 & $3.22 \times 10^{7}$ & $3.27 \times 10^{6}$ & & $9.58 \times 10^{5}$ & $3.23 \times 10^{5}$ & & 1.53 \\
\hline & 0.013 & $1.51 \times 10^{7}$ & $1.82 \times 10^{6}$ & & $5.05 \times 10^{5}$ & $2.32 \times 10^{5}$ & & 1.47 \\
\hline & 0.004 & $7.35 \times 10^{6}$ & $4.78 \times 10^{5}$ & & $2.03 \times 10^{5}$ & $8.59 \times 10^{4}$ & & 1.56 \\
\hline & 0.000 & $3.94 \times 10^{6}$ & $8.55 \times 10^{5}$ & & $1.00 \times 10^{5}$ & $4.14 \times 10^{4}$ & & 1.59 \\
\hline \multirow[t]{7}{*}{8672} & 0.402 & $7.09 \times 10^{8}$ & $1.84 \times 10^{7}$ & 0.998 & $5.42 \times 10^{6}$ & $1.85 \times 10^{6}$ & 0.990 & 2.12 \\
\hline & 0.184 & $2.70 \times 10^{8}$ & $2.30 \times 10^{7}$ & & $2.77 \times 10^{6}$ & $9.99 \times 10^{5}$ & & 1.99 \\
\hline & 0.082 & $1.11 \times 10^{8}$ & $5.42 \times 10^{6}$ & & $1.22 \times 10^{6}$ & $3.01 \times 10^{5}$ & & 1.96 \\
\hline & 0.045 & $5.42 \times 10^{7}$ & $4.58 \times 10^{6}$ & & $5.10 \times 10^{5}$ & $1.04 \times 10^{5}$ & & 2.03 \\
\hline & 0.019 & $2.44 \times 10^{7}$ & $1.25 \times 10^{6}$ & & $2.50 \times 10^{5}$ & $8.75 \times 10^{4}$ & & 1.99 \\
\hline & 0.008 & $1.07 \times 10^{7}$ & $9.01 \times 10^{5}$ & & $1.28 \times 10^{5}$ & $6.84 \times 10^{4}$ & & 1.92 \\
\hline & 0.000 & $5.48 \times 10^{6}$ & $5.29 \times 10^{5}$ & & $5.45 \times 10^{4}$ & $2.44 \times 10^{4}$ & & 2.00 \\
\hline \multirow[t]{7}{*}{$\overline{12146}$} & 0.281 & $3.89 \times 10^{8}$ & $5.45 \times 10^{7}$ & 0.989 & $1.83 \times 10^{6}$ & $6.25 \times 10^{5}$ & 0.968 & 2.33 \\
\hline & 0.135 & $1.51 \times 10^{8}$ & $1.86 \times 10^{7}$ & & $1.09 \times 10^{6}$ & $6.15 \times 10^{5}$ & & 2.14 \\
\hline & 0.052 & $6.80 \times 10^{7}$ & $4.95 \times 10^{6}$ & & $6.17 \times 10^{5}$ & $3.76 \times 10^{5}$ & & 2.04 \\
\hline & 0.030 & $2.99 \times 10^{7}$ & $2.02 \times 10^{6}$ & & $2.52 \times 10^{5}$ & $1.17 \times 10^{5}$ & & 2.07 \\
\hline & 0.012 & $1.48 \times 10^{7}$ & $1.64 \times 10^{6}$ & & $1.38 \times 10^{5}$ & $9.16 \times 10^{4}$ & & 2.03 \\
\hline & 0.006 & $7.37 \times 10^{6}$ & $1.20 \times 10^{6}$ & & $3.22 \times 10^{4}$ & $1.20 \times 10^{4}$ & & 2.36 \\
\hline & 0.000 & $3.26 \times 10^{6}$ & $2.87 \times 10^{5}$ & & $2.48 \times 10^{4}$ & $1.10 \times 10^{4}$ & & 2.12 \\
\hline
\end{tabular}

qPCR: quantitative real-time $\mathrm{PCR}$

a OD: optical density at $600 \mathrm{~nm}$, values represent mean of three independent measurements

${ }^{b}$ Mean number of F57 copies (which is equal to number of Mycobacterium avium subsp. paratuberculosis cells) from a triplicate in a respective dilution

c Standard deviation

${ }^{d}$ Square Spearman's rank correlation coefficient $\left(\mathrm{R}^{2}\right)$ expressing linear dependence of F57qPCR (or culture) counts with OD

${ }^{e}$ Mean number of CFU recovered by culture on solid media from triplicate in a respective dilution

${ }^{f}$ Difference in $\log _{10}$ between mean value gained by F57qPCR and culture expressed as $\log _{10}(\operatorname{copies} / \mathrm{ml})-\log _{10}(C F U / \mathrm{ml})$ 
In summary, it was concluded that using the culture method for MAP enumeration provides two $\log _{10}$ lower counts compared to qPCR. This was shown using three different MAP isolates. Possible reasons for this include the presence of clumps in the suspension and the omission of non-viable cells. MAP counts obtained by qPCR are not influenced by the presence of clumps or the viability of MAP. Based on data, it is recommended using culture and/or qPCR estimations of MAP numbers in experiments when all subsequent counts are performed using the same method(s). It is definitely not recommended to use culture as the standard for qPCR experiments and vice versa.

\section{Abbreviations}

CFU: Colony forming unit; MAP: Mycobacterium avium subsp. paratuberculosis; OD: Optical density; qPCR: Real-time quantitative polymerase chain reaction; RFLP: Restriction fragment length polymorphism.

\section{Acknowledgements}

We would like to thank Adil Hussain for reviewing the language of the manuscript. Technical assistance with OD measurements and culture processing by Marija Kaevska, Ivona Mateska and Sultan Abdul Jawad is also greatly acknowledged. This work was supported by the Grant of the Ministry of Education, Youth and Sports of the Czech Republic "AdmireVet" (CZ.1.05/ 2.1.00/01.0006 and ED 0006/01/01) and the Ministry of Agriculture of the Czech Republic (Grants Nos. MZe0002716202 and QH81065).

\section{Authors' contributions}

PK conceived the whole study and performed measurement of OD and quantification of MAP by QPCR and drafted the manuscript. VB performed the culture experiments and determination of MAP CFU. IP participated on the scientific design of the study. All authors participated intellectually on the writing of this manuscript. All authors read and approved the final manuscript.

\section{Competing interests}

The authors declare that they have no competing interests.

Received: 21 November 2011 Accepted: 22 February 2012 Published: 22 February 2012

\section{References}

1. Gao AL, Odumeru J, Raymond M, Hendrick S, Duffield T, Mutharia L: Comparison of milk culture, direct and nested polymerase chain reaction $(\mathrm{PCR})$ with fecal culture based on samples from dairy herds infected with Mycobacterium avium subsp paratuberculosis. Can I Vet Res 2009, 73:58-64.

2. Ravva SV, Stanker LH: Real-time quantitative PCR detection of Mycobacterium avium subsp. paratuberculosis and differentiation from other mycobacteria using SYBR Green and TaqMan assays. J Microbio/ Methods 2005, 63:305-317.

3. Tasara T, Stephan R: Development of an F57 sequence-based real-time PCR assay for detection of Mycobacterium avium subsp. paratuberculosis in milk. Appl Environ Microbiol 2005, 71:5957-5968.

4. Smith WL, McGarvey KL, Cullor JS: The use of spiral plating and microscopic colony counting for the rapid quantitation of Mycobacterium paratuberculosis. Lett Appl Microbiol 2003, 36:293-296.

5. Hughes VM, Stevenson K, Sharp JM: Improved preparation of high molecular weight DNA for pulsed-field gel electrophoresis from mycobacteria. J Microbiol Methods 2001, 44:209-215.

6. Vansnick E, de Rijk P, Vercammen F, Rigouts L, Portaels F, Geysen D: A DNA sequence capture extraction method for detection of Mycobacterium avium subspecies paratuberculosis in feces and tissue samples. Vet Microbiol 2007, 122:166-171.
7. Slana I, Kralik P, Kralova A, Pavlik I: On-farm spread of Mycobacterium avium subsp. paratuberculosis in raw milk studied by IS900 and F57 competitive real time quantitative PCR and culture examination. Int $J$ Food Microbiol 2008, 128:250-257.

8. Elquezabal N, Bastida F, Sevilla IA, Gonzalez N, Molina E, Garrido JM, Juste RA: Estimation of Mycobacterium avium subsp. paratuberculosis growth parameters: strain characterization and comparison of methods. Appl Environ Microbiol 2011, 77:8615-8624.

9. Forbes BA, Sahm DF, Weissfeld AS: Laboratory methods for detection of antibacterial resistance. Bailey \& Scott's Diagnostic Microbiology. Eleventh edition. St. Louis, MO: Mosby Inc; 2002, 230-231.

10. Janagama HK, Jeong K, Kapur V, Coussens P, Sreevatsan S: Cytokine responses of bovine macrophages to diverse clinical Mycobacterium avium subspecies paratuberculosis strains. BMC Microbiol 2006, 6:10.

11. Bögli-Stuber K, Kohler C, Seitert G, Glanemann B, Antognoli MC, Salman MD, Wittenbrink MM, Wittwer M, Wassenaar T, Jemmi T, BissigChoisat B: Detection of Mycobacterium avium subspecies paratuberculosis in Swiss dairy cattle by real-time PCR and culture: a comparison of the two assays. J Appl Microbiol 2005, 99:587-597.

12. Chui LW, King R, Lu P, Manninen K, Sim J: Evaluation of four DNA extraction methods for the detection of Mycobacterium avium subsp. paratuberculosis by polymerase chain reaction. Diagn Microbiol Infect Dis 2004, 48:39-45.

13. McFarland J: Nephelometer: an instrument for estimating the number of bacteria in suspensions used for calculating the opsonic index and for vaccines. J Am Med Assoc 1907, 14:1176-1178.

14. Khare S, Ficht TA, Santos RL, Romano J, Ficht AR, Zhang S, Grant IR, Libal M Hunter D, Adams LG: Rapid and sensitive detection of Mycobacterium avium subsp. paratuberculosis in bovine milk and feces by a combination of immunomagnetic bead separation-conventional PCR and real-time PCR. J Clin Microbiol 2004, 42:1075-1081.

15. Pickup RW, Rhodes G, Arnott S, Sidi-Boumedine K, Bull TJ, Weightman A, Hurley M, Hermon-Taylor J: Mycobacterium avium subsp. paratuberculosis in the catchment area and water of the River Taff in South Wales, United Kingdom, and its potential relationship to clustering of Crohn's disease cases in the city of Cardiff. Appl Environ Microbiol 2005, 71:2130-2139.

16. Gao A, Mutharia L, Chen S, Rahn K, Odumeru J: Effect of pasteurization on survival of Mycobacterium paratuberculosis in milk. J Dairy Sci 2002, 85:3198-3205

17. Kawaji S, Taylor DL, Mori Y, Whittington RJ: Detection of Mycobacterium avium subsp. paratuberculosis in ovine faeces by direct quantitative PCR has similar or greater sensitivity compared to radiometric culture. Vet Microbiol 2007, 125:36-48.

doi:10.1186/1756-0500-5-114

Cite this article as: Kralik et al:: Enumeration of Mycobacterium avium subsp. paratuberculosis by quantitative real-time PCR, culture on solid media and optical densitometry. BMC Research Notes 2012 5:114.

\section{Submit your next manuscript to BioMed Central and take full advantage of:}

- Convenient online submission

- Thorough peer review

- No space constraints or color figure charges

- Immediate publication on acceptance

- Inclusion in PubMed, CAS, Scopus and Google Scholar

- Research which is freely available for redistribution

Submit your manuscript at www.biomedcentral.com/submit
C Biomed Central 